REVIEW

\title{
Understanding frailty
}

\author{
Frank Lally, Peter Crome
}

Postgrad Med J 2007;83:16-20. doi: 10.1136/pgmj.2006.048587

The term "frailty" is used loosely to describe a range of conditions in older people, including general debility and cognitive impairment. There is no clear consensus on the definition of frailty; however, it is proposed that frailty comprises a collection of biomedical factors which influences an individual's physiological state in a way that reduces his or her capacity to withstand environmental stresses. Only a subset of older people are at risk of becoming frail; these are vulnerable, prone to dependency and have reduced life expectancy. These health outcomes contribute to an increased demand for medical and social care, and are associated with increased economic costs. As demographic trends indicate a rise in the older population, this healthcare burden will increase. This review aims to encapsulate the current debate surrounding the concept of frailty, with emphasis on proposed definitions of frailty which may be relevant to its identification in the clinical setting.

See end of article for authors' affiliations

.....................

Correspondence to: Professor P Crome, Keele University Medical School City General Hospital, Courtyard Annexe, Newcastle Road, Stoke-onTrent, Staffordshire ST4 6QG, UK;

p.crome@keele.ac.uk

Received 13 April 2006 Accepted 19 July 2006
$\mathrm{T}$ he term "frailty" is commonly used rather loosely to describe a range of conditions in older people, including general debility and cognitive impairment. However, growing old is not in itself a prerequisite to becoming frail. Neither does a disability, such as the loss of a limb, lead to frailty in an otherwise physically robust older person. There is, however, a growing consensus among experts that frailty does exist as a distinct syndrome which occurs principally in a subset of older people who are the most vulnerable and who are at increased risk of hospitalisation, dependency and whose life expectancy is reduced. ${ }^{12}$ These adverse health effects in turn contribute to an increased demand for medical and social care and are associated with increased economic and carer costs. For these reasons it is important that clinicians have an awareness of the issues relating to frailty, so that suitable preventive and rehabilitative actions can be taken at the earliest opportunity.

\section{DEFINING FRAILTY}

Several definitions of frailty have been proposed, but there is as yet no formal consensus. The debate has centred on whether frailty should be defined purely in terms of biomedical factors or whether psychosocial factors should also be included.

The common theme of both schools of opinion is that a combination of factors influences frail people's physiological state to the extent that its function is largely reduced. Subsequent exposure to further minor environmental stresses may be sufficient in a frail person to lead to dependency.
Figure 1 summarises the collective views of several authors in the field and shows the way in which both biomedical and psychosocial influences can lead to frailty. Table 1 shows the biomedical factors commonly found in frail individuals.

It is certainly more helpful to many clinicians to identify frailty on the basis of physical rather than psychosocial factors as these are more tangible, more objectively confirmed and are more likely to be treatable by medical means.

The separation of frailty from both comorbidity (multiple pathology) and disability is supported by the identification of biomedical factors associated only with the former condition. Additionally, a significant proportion of frail older people do not meet the common criteria for either comorbidity or disability $^{3}$ (fig 2).

The relationship between frailty, comorbidity and disability was explored in an early study by Fried et al. ${ }^{1}$ These authors concluded that frailty was not synonymous with either comorbidity or disability, but that comorbidity was a risk factor for frailty and that disability was an outcome of it. This relationship was explored further in a large prospective study of older women, ${ }^{4}$ which reported findings similar to the Fried study and supported the robustness of their concept of frailty as a distinct clinical syndrome with poor prognosis. Subsequently, Boyd et al identified frailty as being strongly and independently associated with the onset of dependence in activities of daily living.

The World Health Organization is currently attempting to define frailty, and has identified a number of potential indicators. These have been added to the International Classification of Functioning, Disability and Health. ${ }^{5}$ However, the indicators have so far been based solely on one review paper. ${ }^{6}$ In light of the conflicting views on the diagnosis of frailty, it seems unlikely that the proposed definition will be accepted globally at this stage.

\section{EPIDEMIOLOGY}

As there is no generally accepted definition of frailty, it is not possible to quantify accurately the numbers of frail individuals in the population. In the UK there have been no studies that have formally investigated the prevalence of this condition. However, a number of studies have been conducted in the US. One which used a selfreporting screening instrument was based on four predictors of frailty: age, health conditions interfering with activities of daily living, requiring assistance in taking drugs and in bathing. The

Abbreviations: $C M V$, cytomegalovirus; $C R P, C$ reactive protein 


\begin{tabular}{ll}
$\begin{array}{l}\text { Table } 1 \\
\text { contribute towards onset of frailty }\end{array}$ \\
\hline Clinical & Pathophysiological \\
\hline Weakness & Insulin resistance \\
Weight loss (unintentional) & Increased blood-clotting activity \\
Viral infection & Sarcopenia \\
Obesity & Decreased $\mathrm{VO}_{2}$ max \\
Comorbidity & Lowered testosterone \\
Cognitive impairment & \\
Fatigue & \\
Anaemia & \\
Inflammation & \\
\hline $\mathrm{VO}_{2}$ max, maximal oxygen consumption.
\end{tabular}

study showed rates of frailty ranging from $55 \%$ for persons aged 65 years to $96 \%$ for persons aged $\geqslant 90$ years. $^{7}$

Other estimates from several studies using a variety of definitions of frailty reported prevalence figures in communitybased individuals ranging from $7 \%$ to $32 \%$, with a higher prevalence in women. ${ }^{138}$

It has also been postulated that there is a continuum of the severity of frailty, ${ }^{6}$ and several studies have identified subpopulations termed "intermediate". One study describes the intermediate group as having 1 or 2 of 5 frailty index components (discussed later). This "intermediate" group of people do not meet a postulated formal definition of frailty, but may represent a group to target for preventive interventions. This is important because they made up $46 \%$ of the total cohort at baseline. ${ }^{1}$

A recent community-based study ${ }^{9}$ concluded that frailty was a dynamic process characterised by transitions between predefined frailty states over time. Although deteriorations to less frail states were identified (up to $23 \%$ ), a change to a greater state of frailty was more commonly observed (up to $43.3 \%)$.

\section{PREDICTORS}

A large number of predictors of frailty have been proposed. Table 2 shows those predictors most often cited in the literature. Not surprisingly, there is substantial overlap between these predictive factors and the biomedical features present in older people broadly considered to be frail.

Several studies ${ }^{10-12}$ have proposed possible markers of frailty for use as a frailty index that may be used to aid diagnosis. One such study using a quantifiable index of frailty in a Hong Kong population $^{13}$ has shown the effectiveness of this approach across cultural divides and different healthcare systems.

An often cited model ${ }^{13}$ uses a cluster of predictors (table 3) that identifies a "phenotype" of frailty. The authors propose that the presence of three or more of these components indicates frailty.

As mentioned earlier, the presence of $1-2$ predictors is indicative of an "intermediate at risk" group that may be targeted for intervention. The frailty phenotype identified by these predictors has been subsequently validated using data from the Cardiovascular Health Study. ${ }^{14}$ The presence of this frailty phenotype at baseline predicted five adverse health outcomes at both 3 and 7 years (table 4). After adjustment for covariates, the frailty phenotype was found to be an independent predictor of all adverse health outcomes $(p \leqslant 0.05)$ except falls $(\mathrm{p}=0.06)$.

Predictors such as those described above do not include psychological, social and environmental factors which are thought by some to be important contributors of frailty. ${ }^{1015} 16$ The relevance of including such factors as diagnostic or prognostic tools remains to be determined.

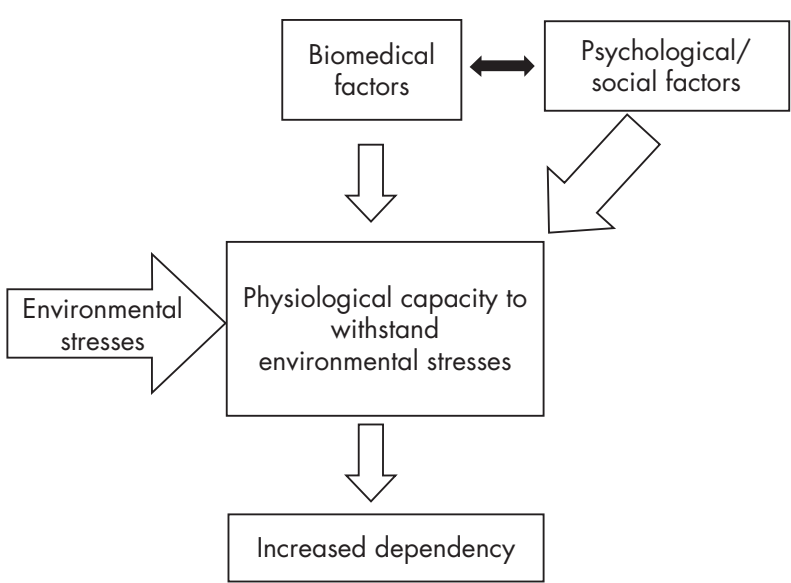

Figure 1 Possible mechanisms for the reduction of physiological capacity to withstand stress, leading to frailty.

Older people accrue age-related adverse changes such as illnesses, muscle loss and reduced strength. It has been suggested that the presence of these alone could be used as predictors of frailty. However, people do not accumulate the same changes at the same rate. This variability has led to disagreement that age-related changes can be used as a frailty index at the clinical or population level. ${ }^{8}{ }^{17}$ Similarly, it has been proposed that both fitness and frailty can be estimated by comparing the number of symptoms and signs present in an individual. ${ }^{12}$ These signs and symptoms are referred to as accumulated deficits, and a selection of these deficits could form the basis of a frailty index that could be used in the clinical setting.

A number of authors have now published their ideas of what should constitute a practical frailty index. ${ }^{34812}$ 17-24 However, they all differ in one way or another, without there being a strong consensus for a particular model.

\section{Pathophysiological predictors}

Significantly higher levels of inflammatory markers such as $\mathrm{C}$ reactive protein (CRP) and interleukin-6 (IL6) have been found in frail individuals when compared with non-frail older people. ${ }^{1}$ It has been suggested that such stimulation of the immune system may be through chronic low-level infections which may predispose an individual to frailty..$^{26}$ It has also been hypothesised that chronic inflammation may itself result as a failure in the regulation of the immune system due to the process of ageing. ${ }^{27}$ The term immunosenescence has been coined to describe the decreased responsiveness in the immune

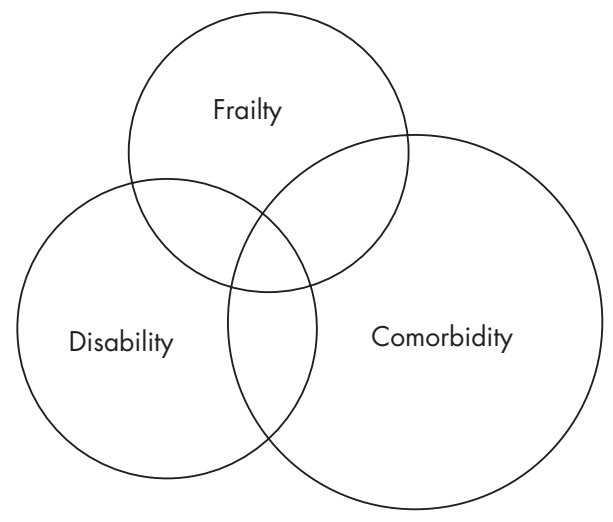

Figure 2 The association between frailty, disability and comorbidity. 


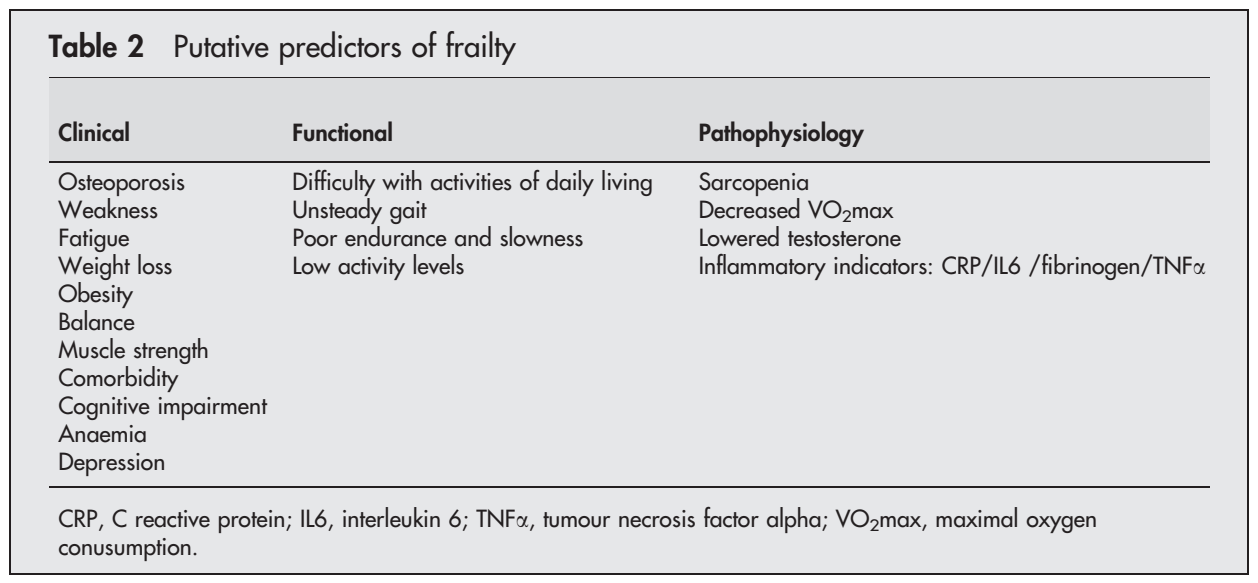

system of some elderly people, and it is proposed that viral infections in younger years may predispose to immunosenescence in later life. $^{26}$ Interest has also been generated by the observation that older people who are seropositive for cytomegalovirus (CMV) seem to be more at risk of manifesting immune system disorders than CMV-negative individuals of the same age group. Independent longitudinal studies of a population-based cohort of the very old people in Sweden over the past decade have led to the emerging concept of an "immune risk phenotype" ${ }^{28}$ Those with this phenotype, which itself is found to be associated with CMV seropositivity, have an increased mortality. Clearly, more evidence is required to substantiate these ideas. There is no doubt that a simple biological diagnostic marker for frailty would be a very useful tool if there was an effective treatment to prevent or treat frailty.

In addition to CRP and IL6, several other potential biological markers for frailty have been identified. These include endocrine and inflammatory markers such as factor VIII, ${ }^{29}{ }^{30}$ haemoglobin ${ }^{31}$ and plasma hypertonicity. ${ }^{32} 33$

Just as is the case with the clinical phenotype, the absence of a standardised definition for frailty makes it difficult to identify putative biological markers.

\section{PREVENTING FRAILTY Intervention}

Most studies on preventing frailty have been conducted after acute events such as stroke or fracture. Relatively few studies have been undertaken investigating the effects of intervention on functional decline once frailty has developed. Such studies that have been carried out on frail older people have shown that it is possible to prevent functional decline. One intervention study of physically frail people ${ }^{34}$ included physical treatment that targeted underlying impairments in physical abilities, including balance and muscle strength. Disability scores at baseline were 2.3 and 2.8 in the intervention and control groups, respectively. The authors reported reduction in

\begin{tabular}{|c|c|}
\hline Frailty characteristic & Cardiovascular Health Study measure \\
\hline $\begin{array}{l}\text { Weight loss (unintentional), } \\
\text { sarcopenia } \\
\text { Weakness, fatigue } \\
\text { Poor endurance } \\
\text { Low activity levels } \\
\text { Slowness }\end{array}$ & $\begin{array}{l}\text { Baseline, }>10 \mathrm{lb} \text { lost in the previous } \\
\text { year } \\
\text { Grip strength adjusted for BMI/gender } \\
\text { Self-reported exhaustion } \\
\text { kcal/week } \\
\text { Walking time by gender/height }\end{array}$ \\
\hline
\end{tabular}

functional decline in the intervention group at 12 months (score 2.7) compared with the control group (4.2). Benefits were not reported in those with severe frailty at baseline.

The beneficial effects of exercise in the older population have been widely publicised. As inactivity and muscle weakness have been identified as major determinants in the onset of frailty, it is not difficult to imagine a simple and cost-effective exerciseintervention measure that may slow or reverse the process. A recently published cross-sectional study of older people in longterm care facilities ${ }^{35}$ examined the relationship between components of physical fitness and functional performance. The authors concluded that exercise programmes for residents, which included coordination maintenance, may prevent or slow down the decline in physical functioning.

Another potential benefit of exercise is the interesting observation made in a study on inflammatory markers, ${ }^{33}$ that elderly participants who were more physically active had lower levels of IL6 and CRP. A separate study ${ }^{36}$ found a decrease in tumour necrosis factor alpha as a result of resistance exercise, thus indicating an anti-inflammatory component to exercise.

Positive psychological states may also be beneficial in the prevention of frailty. ${ }^{37}$ It has been suggested that the concept of positive health is more than simply the absence of disability or disease. Thus, psychological approaches aimed at the production of a positive psychological state in those at risk of frailty may strengthen other interventions aimed at stopping functional decline. ${ }^{37}$

\section{DRUGS AND TREATMENT}

At present, there is no specific treatment for the condition of frailty. Treatment regimens for those who are frail or at risk should be aimed at any specific disorders that may be contributing to their frailty. Table 5 lists some suggested therapeutic interventions, although it should be noted that not all have been proved to benefit frailty.

\section{CONCLUSIONS}

There is clearly a need for consensus on the clinical definition of frailty, as the ability to diagnose and measure the development and severity of the condition is a prerequisite for the formulation of healthcare policy and for the evaluation of clinical interventions. Similarly, confirmation of the existence of a prefrailty or "intermediate" group of patients may be important for prevention strategies.

Frailty is complex in its manifestations and there is as yet no generic treatment. Therefore, therapeutic interventions need to be tailored to the individual. In older people, a comprehensive geriatric assessment should form the basis of the diagnostic process, concentrating treatments on those most likely to produce benefit while avoiding those treatments most likely to 
Table 4 Adverse health outcomes (all values shown are covariate adjusted)

\begin{tabular}{|c|c|c|c|c|}
\hline \multirow[b]{2}{*}{ Outcome } & \multicolumn{2}{|l|}{3 years } & \multicolumn{2}{|l|}{7 years } \\
\hline & Intermediate & Frail & Intermediate & Frail \\
\hline Incident fall & $p=0.056$ & $p=0.054$ & $p=0.045$ & $p=0.064$ \\
\hline Worsening mobility & $p=0.001$ & $p=0.001$ & $p=0.001$ & $p=0.001$ \\
\hline Worsening ADL disability & $p=0.001$ & $p=0.001$ & $p=0.001$ & $p=0.001$ \\
\hline First hospitalisation & $p=0.014$ & $p=0.004$ & $p=0.005$ & $p=0.008$ \\
\hline Death & $p=0.001$ & $p=0.001$ & $p=0.006$ & $p=0.001$ \\
\hline
\end{tabular}

Table 5 Disorders that may lead to increasing frailty and potential treatments

\begin{tabular}{|c|c|}
\hline Condition/disorder & Treatment \\
\hline Falls/fractures & $\begin{array}{l}\text { Vitamin D } \\
\text { Calcium treatment } \\
\text { Exercise }\end{array}$ \\
\hline Depression & $\begin{array}{l}\text { Exercise } \\
\text { Social interaction } \\
\text { Counselling } \\
\text { Psychotherapy } \\
\text { Antidepressants }\end{array}$ \\
\hline Lowered testosterone (males) & Replacement therapy \\
\hline Cognitive impairment & $\begin{array}{l}\text { Cholinesterase inhibitors } \\
\text { Exercise }\end{array}$ \\
\hline $\begin{array}{l}\text { Hypothyroidism } \\
\text { Inflammation/muscle strength }\end{array}$ & $\begin{array}{l}\text { L-thyroxine } \\
\text { Exercise } \\
\text { Statins/ACE inhibitors }\end{array}$ \\
\hline Type 2 diabetes & $\begin{array}{l}\text { Thiazolidinedione } \\
\text { Anti-glycaemics }\end{array}$ \\
\hline Blood-clotting activity & Aspirin \\
\hline Poor nutrition & Dietary regulation \\
\hline CHD & $\begin{array}{l}\text { Antihypertensives } \\
\text { Aspirin } \\
\text { Statins }\end{array}$ \\
\hline Anaemia & $\begin{array}{l}\text { Haematinic replacement therapy } \\
\text { Recombinant human erythropoietin }\end{array}$ \\
\hline Arthritis & $\begin{array}{l}\text { NSAIDs } \\
\text { Steroids }\end{array}$ \\
\hline
\end{tabular}

cause harm. ${ }^{38}$ Of all the postulated treatments, exercise appears to be the most universally applicable.

The priorities for research are large and include further understanding of the biological and psychosocial basis of frailty, agreeing prognostic and diagnostic criteria, as well as evaluating the effects of therapeutic interventions.

The cost of ageing is high; about one third of the health expenditure in industrialised countries is spent on people $>70$ years. ${ }^{39}$ As the number of people over that age increases worldwide, the proportion of those termed frail will also increase, resulting in an escalation of healthcare costs. One way to prevent this is to plan for the proper clinical assessment of frailty, followed by a multidisciplinary approach to intervention and management.

Several prominent geriatricians in the US have been quoted ${ }^{40}$ as saying that perhaps one day, frailty may become an official International Classification of Diseases diagnosis with approved treatments and interventions. We may well be closer to reaching that goal.

\section{Authors' affiliations}

Frank Lally, Peter Crome, Keele University Medical School, City General Hospital, Stoke-on-Trent, Staffordshire, UK

Competing interests: None declared.

\section{REFERENCES}

1 Fried LP, Tangen CM, Walston J, et al. Frailty in older adults: evidence for a phenotype. J Gerontol A Biol Sci Med Sci 2001;56:M146-57.

2 Boyd CM, Xue QL, Simpson CF, et al. Frailty, hospitalization, and progression of disability in a cohort of disabled older women. Am J Med 2005;1 18:1225-31.

3 Fried LP, Ferrucci L, Darer J, et al. Untangling the concepts of disability, frailty, and comorbidity: implications for improved targeting and care. J Gerontol A Biol Sci Med Sci 2004;59:M255-63.

4 Fugate Woods N, LaCroix AZ, Gray SL, et al. Frailty: emergence and consequences in women aged 65 and older in the Women's Health Initiative Observational Study. J Am Geriatr Soc 2005;53:1321-30.

5 World Health Organization. International classification of functioning, disability and health, WHO, 2006.

6 Hogan DB, MacKnight C, Bergman H. Models, definitions, and criteria of frailty. Aging Clin Exp Res 2003;15(Suppl): 1-29.

7 Brody KK, Johnson RE, Douglas RL. Evaluation of a self-report screening instrument to predict frailty outcomes in aging populations. Gerontologist 1997;37:182-91

8 Mitnitski A, Song X, Skoog I, et al. Relative fitness and frailty of elderly men and women in developed countries and their relationship with mortality. J Am Geriatr Soc 2005;53:1069-70.

9 Gill TM, Gahbaver EA, Allore HG, et al. Transitions between frailty states among community-living older persons. Arch Intern Med 2006; 166:418-23.

10 Puts MTE, Lips P. Deeg DJH. Sex differences in the risk of frailty for mortality independent of disability and chronic diseases. J Am Geriatr Soc 2005;53:40-7.

11 Paw A, Dekker JM, Feskens EJM, et al. How to select a frail elderly population? A comparison of three working definitions. J Clin Epidemiol 1999;52:1015-21.

12 Mitnitski A, Graham J, Mogilner A, et al. Frailty, fitness and late-life mortality in relation to chronological and biological age. BMC Geriatr 2002;2:1.

13 Woo J, Goggins W, Sham A, et al. Public health significance of the frailty index. Disabil Rehabil 2006;28:515-21.

14 Fried LP, Borhani NO, Enright $P$, et al. The Cardiovascular Health Study: design and rationale. Ann Epidemiol 1991;1:263-76.

15 Woo J, Goggins W, Sham A, et al. Social determinants of frailty. Gerontology 2005;51:402-08.

16 Markle-Reid M, Browne G. Conceptualizations of frailty in relation to older adults. J Adv Nurs 2003:44:58-68.

17 Studenski S, Hayes RP, Leibowitz RQ, et al. Clinical global impression of change in physical frailty: development of a measure based on clinical judgment. J Am Geriatr Soc 2004;52:1560-66.

18 Rockwood K, Song X, MacKnight C, et al. A global clinical measure of fitness and frailty in elderly people. CMAJ 2005;173:489-95.

19 Fisher AL. Just what defines frailty? J Am Geriatr Soc 2000;53:2229-30.

20 Rockwood K, Stadnyk K, MacKnight C, et al. A brief clinical instrument to classify frailty in elderly people. Lancet 1999;353:205-6.

21 Rockwood K. Frailty and its definition: a worthy challenge. J Am Geriatr Soc 2005;53:1069-70.

22 Saliba D, Orlando $M$, Wenger NS, et al. Identifying a short functional disability screen for older persons. J Gerontol A Biol Sci Med Sci 2000;55:M750-6.

23 Puts MT, Lips P, Deeg DJ. Static and dynamic measures of frailty predicted decline in performance-based and self-reported physical functioning. J Clin Epidemiol 2005;58: 1188-98.

24 Rockwood K, Mogilner A, Mitnitski A. Changes with age in the distribution of a frailty index. Mech Ageing Dev 2004;125:517-19.

25 Cohen $\mathrm{HJ}$. In search of the underlying mechanisms of frailty [editorial]. J Gerontol A Biol Sci Med Sci 2000;55:M706-8.

26 Pawelec G. Immunosenescence and vaccination. Immun Ageing 2005;2:16.

27 Hamerman D. Toward an understanding of frailty. Ann Intern Med 1999;130:945-50.

28 Ferguson FG, Wikby A, Maxson P, et al. Immune parameters in a longitudinal study of a very old population of Swedish people: a comparison between survivors and nonsurvivors. J Gerontol A Biol Sci Med Sci 1995:50:B378-82.

29 Walston J, McBurnie MA, Newman A, et al. Frailty and activation of the inflammation and coagulation systems with and without clinical comorbidities: results from the Cardiovascular Health Study. Arch Intern Med 2002;162:2333-41.

30 Puts MTE, Visser M, Twisk JWR, et al. Endocrine and inflammatory markers as predictors of frailty. Clin Endocrinol 2005;63:403-11.

31 Leng S, Chaves P, Koenig K, et al. Serum interleukin- 6 and hemoglobin as physiological correlates in the geriatric syndrome of frailty: a pilot study. J Am Geriatr Soc 2002;50:1268-71. 
32 Stookey JD, Purser JL, Pieper CF, et al. Plasma hypertonicity: another marker of frailty? J Am Geriatr Soc 2004;52:1313-20.

33 Taaffe DR, Harris TB, Ferrucci $L$, et al. Cross-sectional and prospective relationships of interleukin- 6 and $C$ reactive protein with physical performance in elderly persons: MacArthur studies of successful aging. J Gerontol A Biol Sci Med Sci 2000;55:M709-15.

34 Gill TM, Baker DI, Gottschalk M, et al. A program to prevent functional decline in physically frail, elderly persons who live at home. NEngl J Med 2002;347:1068-74.

35 Singh AS, Chin APM, Bosscher RJ, et al. Cross-sectional relationship between physical fitness components and functional performance in older persons living in long-term care facilities. BMC Geriatr 2006;6:4.
36 Greiwe JS, Cheng BO, Rubin DC, et al. Resistance exercise decreases skeletal muscle tumor necrosis factor (alpha) in frail elderly humans. FASEB J 2001;15:475-82.

37 Ostir GV, Ottenbacher KJ, Markides KS. Onset of frailty in older adults and the protective role of positive affect. Psychol Aging 2004;19:402-8.

38 Stuck AE, Siu AL, Wieland GD, et al. Comprehensive geriatric assessment: a meta-analysis of controlled trials. Lancet 1993;342:1032-6.

39 Polder JJ, Achterberg PW. Cost of illness in The Netherlands. The Netherlands: National Institute for Health and Environment, 2004

40 Wilson JF. Frailty - and its dangerous effects - might be preventable. Ann Intern Med 2004;141:489-92. 